\title{
Nestling begging calls increase predation risk by corvids
}

\author{
Magne Husby* \\ Section of Science, Nord University, N-7600 Levanger, Norway \\ Submitted: June 5, 2018. Final revision received: July 24, 2018. Accepted: August 7, 2018
}

\begin{abstract}
Despite nest predation being the most common cause of breeding failure in open-nesting birds, we have little insight into the cues used by nest predators when they search for nests. So far we have assumed that nest-predating birds are visually oriented while mammal predators to a large extent use scent and auditory cues like nestling begging calls. To evaluate how important nestling begging calls are for corvid nest predators searching for nests, I used artificial nests, which made it possible to find the real costs of the begging without mitigation by parental and nestling behavior. I used paired artificial nests, one with and one without nestling begging call playback. Within 10 days, $62.9 \%$ of the nests were predated. The analyses showed that nests with begging calls suffered a significantly higher predation rate than nests without begging calls, especially when the nests were placed close to corvid nests. Moreover, nests with begging calls were predated significantly earlier than nests without begging calls. In artificial nest pairs with both nests predated but on different days, nests with begging calls were predated first. In nest pairs with only one predated nest, nests with begging calls were predated most often. This experiment shows that nestling begging calls imply a cost in terms of increased and earlier nest predation, and that corvids use nestling begging calls as a cue to find and depredate bird nests, challenging earlier expectations.
\end{abstract}

\section{Keywords}

Begging calls; behavioral ecology; Corvus cornix; Cyanistes caeruleus; nest predation; Pica pica; predator cognition; predator-prey interaction; urban rural

\section{Introduction}

Nest predation is the most common cause of breeding failure in many bird species, and can be responsible for $80 \%$ or more of the losses (Nolan, 1963; Ricklefs, 1969; Gates \& Gysel, 1978; Martin, 1993a, b; Hewitt et al., 2001). This implies a reduction in fecundity, which is the primary demographic parameter influenc-

*) E-mail: magne.husby@ nord.no 
ing population dynamics and life history parameters of songbirds (Temple \& Cary, 1988; Martin, 1995). Adaptations against possible negative effects of nest predation include variation in nest site selection, clutch size, eggshell coloration, mean egg size, egg size variation with laying sequence in the clutch, parental feeding rate and nest defense strategies (Slagsvold et al., 1984; Martin et al., 2000a; Kilner, 2006; Lima, 2009). In addition, nestlings can reduce the begging loudness (volume) and increase the frequency (pitch) of vocalization in areas with high predation rates, making it more difficult for the predators to find the nest (Briskie et al., 1999). An increase in nestling begging volume and frequency, as well as by playback from speakers, normally increases parental feeding rate as intended (Bengtsson \& Rydén, 1983; Hinde \& Kilner, 2007; Tarwater et al., 2009), but not always (Santema et al., 2017). The drawback is often that higher parental activity seems to increase nest predation rate (Martin et al., 2000b; Badyaev \& Ghalambor, 2001; Muchai \& du Plessis, 2005). According to theoretical models of the evolution of begging in nestling passerines, begging is costly because of the expended energy or because of increased nest predation rates (Magrath et al., 2010). Acoustic signal evolution might therefore be subject to conflicting selection pressures between maximizing communication to intended receivers and minimizing communication to unintended ones (Magrath et al., 2010; Searcy \& Yasukawa, 2017). There are, however, few empirical studies showing whether the cost of intensive begging is associated with increased predation rate (Leech \& Leonard, 1997; Magrath et al., 2010). It might seem obvious that nestling begging calls attract acoustically oriented predators, but this is not necessarily true (Magrath et al., 2010). Predators have varying sensory abilities, and their focus towards nest searching and the availability of alternative prey vary in space and time (Magrath et al., 2010). Despite the fact that nestling begging calls seem to increase predation rate on individual nests, there is little evidence that nest predation influences population dynamics in passerines (Madden et al., 2015).

According to a review by Magrath et al. (2010), only five experiments have been conducted with artificial nests and playback of nestling calls, and all five showed increased nest predation rates as an effect of the begging sounds (Haskell, 1994, 1999; Leech \& Leonard, 1997; Dearborn, 1999; McDonald et al., 2009). Only three of the experiments used plasticine eggs in an attempt to reveal whether mammals or birds were the main nest predators. In one of the experiments, only mammals were involved (Haskell, 1999). In another experiment, eight nests out of ten with known predators were predated by mammals, one by a snake and one by a bird (Dearborn, 1999). In the third experiment, birds predated 32 nests and rodents predated 71 when the nest predator was positively identified (McDonald et al., 2009). These nestling begging call experiments suggest that mammals are the dominant nest predators. However, one of the investigations shows that depredation by birds increase as begging calls get louder (McDonald et al., 2009), and it is therefore important to investigate if birds like corvids use auditory cues as a method in their search for nests to depredate. In my study area, it is well known that both mammals 
and birds predate artificial nests without nestling sounds (Hoset \& Husby, 2018). At least, there is no doubt that most birds have the sensory apparatus needed to find the direction to nestling begging sounds (Birkhead, 2012).

Normally it is rare to observe nest predation in natural ecosystems, and despite many different methods used in an effort to identify nest predators in the last decades (Cutler \& Swann, 1999; Colyn et al., 2018), it is a major challenge to understand how they find the nests. Despite the high importance of nest predation in avian ecology, hardly any experiments have been aimed at identifying the cues used by predators (Pelech et al., 2010). How predators localize avian nests is poorly understood (Santisteban et al., 2002). In an experiment with fish crows (Corvus ossifragus), a common nest predator in the southeastern United States, only nest visibility and not auditory or olfactory cues influenced predation rate on artificial nests (Santisteban et al., 2002). The authors claim that their results demonstrate that fish crows are visually oriented. In fact, it is generally assumed that avian nest predators use sight in their search for nests to depredate, and that mammalian predators are the principal unintended receivers of nestling begging calls (Magrath et al., 2010; Ibanez-Alamo et al., 2015). Findings that the cost of begging on predation is high for nests on the ground accessed by both many mammal and bird nest predators but not for nests in trees, which are most easily accessed by bird predators (Haskell, 1994), indicate that mammalian predators are the principal predators that benefit most by using auditory cues on nestling begging calls.

The purpose of this study was to examine whether the sounds of begging nestlings increase the nest predation risk and/or reduce the time to a predation event. The use of artificial nests with playbacks of nestling calls was recommended to unveil the nest predation cost of begging calls itself without intervening variables (Magrath et al., 2010). Therefore, using artificial nests, I particularly wanted to investigate if corvids can use auditory cues to find such nests. My hypothesis was that nest predation risk would be higher for nests with begging calls. According to the descriptions above, it is not clear whether corvids increase their predation on nests with begging calls. If they do, I would also expect that within pairs of artificial nests where both nests are predated, the one with sound would be predated first. In addition, I would expect that in pairs where only one nest is predated, the ones with nestling begging calls should be predated more frequently than nests without sounds. If this were the case for areas where corvids are the main nest predators, it would strongly suggest that corvids use auditory cues when they search for nests to depredate.

\section{Methods}

Study areas

The experiments (see details below) were performed in two study areas, one in the central part and the other in the southwestern part of Norway (A and B, respectively, in Fig. 1). Artificial nests were placed in two different habitats; 1) forest 


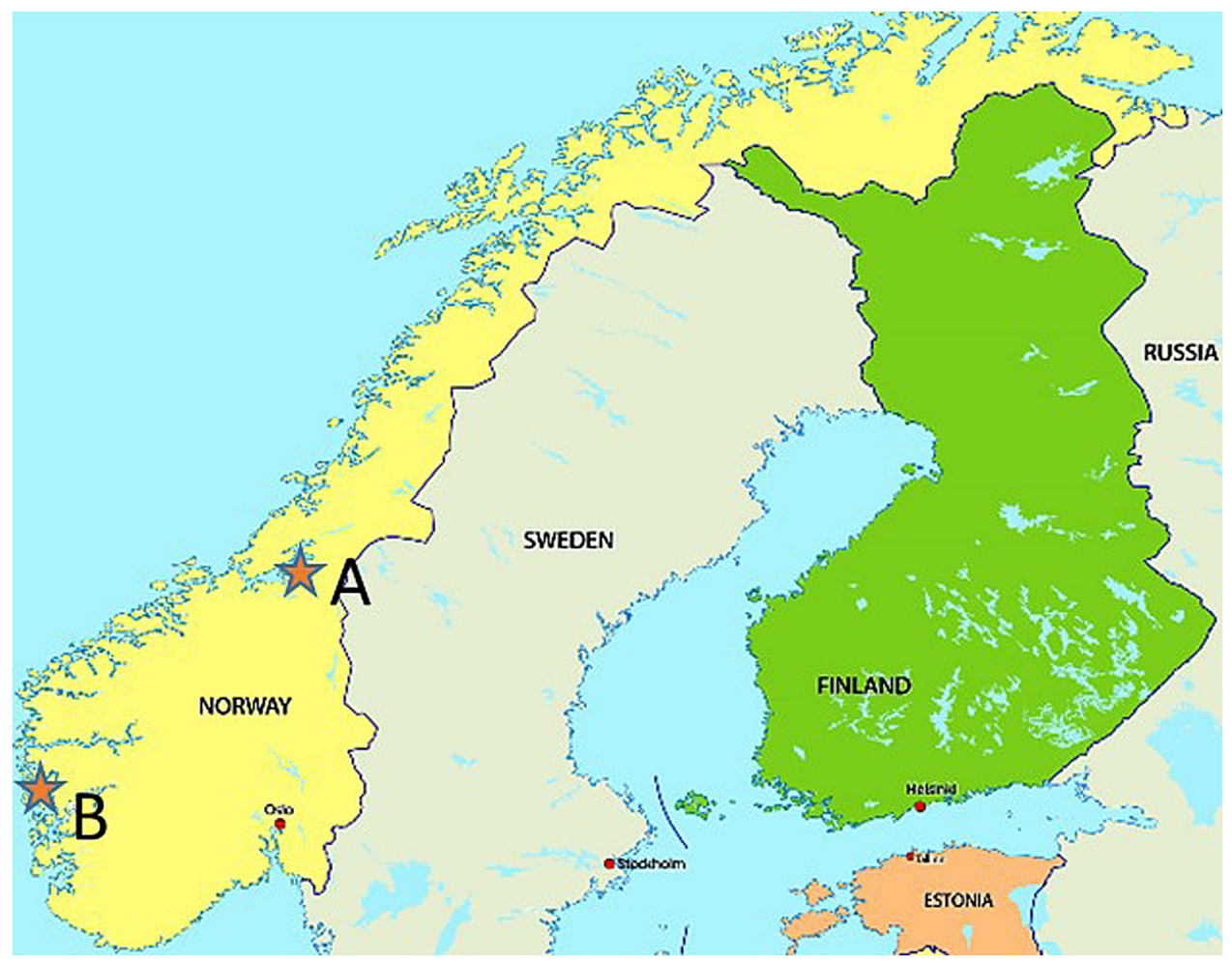

Figure 1. Map of Norway with the two regions with predation rate experiments. A is in rural areas and includes one city in Trøndelag; B is in the city of Bergen.

patches mainly in the central part and 2) human settlement areas in both the central and southwestern parts. In the central part of Norway, all study sites belong to the western part of the mid-boreal forest zone, which constitutes a mosaic landscape with forest, forest patches, farmland, lakes and ocean, mires and human settlements. The forests used are separated in different patches. They are dominated by Norwegian spruce Picea abies, but include some deciduous and other conifer trees. In both study areas, human settlements were mostly gardens with a house for one or a few families, and only relatively small forest patches and parks in the surroundings. There were also small areas not suited for the experiment (for example parks, railways, roads, lakes, and areas with no active corvid nest). Deciduous trees with few conifer trees dominated sites in the southwestern area. In the central part of Norway, there were also many conifer trees in the gardens but relatively more deciduous trees than in the forests. In the forest habitat the artificial nests were placed in clearly defined forest patches, while in the human settlement habitat the artificial nests were placed close to active corvid nests and therefore spaced more or less continuously and not in clearly defined sites.

Typical nest predators of open-cup nests in the study areas are stoat Mustela erminea, least weasel Mustela nivalis nivalis, European pine marten Martes martes, 
red squirrel Sciurus vulgaris, red fox Vulpes vulpes, badger Meles meles, Eurasian jay Garrulus glandarius, Eurasian magpie Pica pica, hooded crow Corvus cornix and common raven Corvus corax. Stoat and particularly least weasel are rodent specialists that predominantly eat birds and eggs as alternative food when rodent numbers are low (Korpimäki et al., 1991). In human settlement areas, cats Felis silvestris catus and especially dogs Canis familiaris are more common than in the forested areas. They can cause nest predation both directly and indirectly (Langston et al., 2007; Guppy et al., 2017).

\section{Artificial nest experiments}

All artificial nests were made of wire baskets lined with dry grass and moss and were attached to branches with iron wire. Nests were open-cup nests, about $11 \mathrm{~cm}$ in outer diameter, about $4 \mathrm{~cm}$ deep, and therefore similar to nests of several open-cup nesters in the study areas. The wire cup was visible from beneath, but completely hidden by nesting material from above and therefore the appearance was quite similar to that of a natural nest. In each nest, I put one fresh quail Coturnix coturnix egg and one plasticine egg. Quail eggs are found to be acceptable for studies of nest predation rates (Sieving, 1992; Lewis \& Montevecchi, 1999), but rates are dependent on the size of the quail egg relative to the size of the nest predators in the actual area (Haskell, 1995). The plasticine eggs were a mixture of grey and green plasticine and were similar in size and shape to the quail eggs. The plasticine eggs were attached to a branch under the nest by a metal wire with a barb inside the egg.

To evaluate the effects of nestling begging calls on artificial nest predation rates, I conducted experiments with paired nests, one with and one without playback sound of nestling begging calls (Table 1). I used two different habitats, 1) forest patches and 2) sites close to active corvid nests in human settlement areas. In forests, nests were placed in areas with low human activity, and away from tracks.

\section{Table 1.}

Number of individual artificial nests with and without begging call playback, by study year. When playback calls are present, numbers are provided for weak sound and medium sound strength separately. Number of sites is the number of different forests patches used the two first years, while the human settlement areas from 2003 onwards were more or less continuous each year. The table includes individual nests, but nest with and without sounds are always in pairs.

\begin{tabular}{lccccr}
\hline Year & Number of sites & Without playback & Weak volume & Medium volume & Total \\
\hline 2001 & 21 & 30 & 20 & 10 & 60 \\
2002 & 21 & 56 & 11 & 45 & 112 \\
2003 & & 38 & 0 & 38 & 76 \\
2004 & 26 & 0 & 26 & 52 \\
2010 & 4 & 0 & 4 & 8 \\
2014 & 36 & 0 & 159 & 72 \\
Total & 190 & 31 & & 380 \\
\hline
\end{tabular}


Each pair of nests was placed a minimum of $100 \mathrm{~m}$ away from the closest nest in another pair, and the two nests in a pair were placed a minimum of $50 \mathrm{~m}$ apart from each other. The two nests in a pair were located closer to each other than to nests in any other pair. I consider these distances as adequate to treat each pair of nests as an independent unit. In each forest patch, the number of pairs of artificial nests varied from one pair in small forest patches to seven pairs in larger patches. In human settlement areas, I searched for active nests of Eurasian magpies and hooded crows where it was possible to place two artificial nests in a similar manner. I placed two artificial nests in each corvid territory, about $30 \mathrm{~m}$ from the corvid nest and at opposite sides so the distance between the two artificial nests was about $60 \mathrm{~m}$. Both the Eurasian magpie and the hooded crow are highly territorial with normally more than $100 \mathrm{~m}$ between neighbouring nests (Cramp \& Perrins, 1994; Husby \& Olsen, 2017), and therefore each pair of artificial nests placed close to corvid nests is considered to be an independent unit. In the statistical analyses, it is taken into consideration that the predation probabilities of the two nests within a pair are not necessarily independent. I placed all nests in all areas about $0.5 \mathrm{~m}$ above the ground, and I investigated both nests in a pair at every visit.

I did not use rubber boots or gloves to avoid leaving scents at the nest, since the risk of predators learning to associate human scent or activity with artificial nests is small (Sloan et al., 1998; Roos, 2002). As I used the same method across all study areas and all nests, any potential bias caused by my activity increasing the predator's ability to find nests should be minimal or at least equal for all nests. The only difference between the two nests in a pair should be the nestling begging calls or silence.

The artificial nest experiments were conducted from the beginning of March to the end of June. I started the experiment on day 0 , simultaneously for both nests in a pair, and continued to day 10 if the nest was not predated earlier. In 2001 and 2002 I investigated the nests daily, and in later years I investigated every nest two times per day; in the morning and in the afternoon and sometimes also during the middle of the day. On some days it was not possible to visit all nests, but no nests visited less often than eight times during the 10-day period are included in this investigation. At every visit, the nest status was noted. If predated, the plasticine eggs were investigated using a magnifying glass to search for marks that could identify the nest predator. The time lapse from the start of nest exposure until predation was measured in hours. Because the exact times of nest exposure and of each monitoring check were not recorded, the number of hours calculated depended on how often each nest was visited. For daily visits, 24 hours were added to the time lapse calculation for each visit until predation. If nests were visited twice per day, 12 hours were added for each visit, and if nests were visited three times per day, 8 hours were added to the calculation for each visit until predation. Each nest could receive a mixture of monitoring visitation rates. These definitions are based on the assumption that the nest was predated immediately before my visit in these calculations. 
Table 2.

The relationship between artificial nest placement, number of nests with no begging call playback or with two strengths of begging call playback. Predation rates after 10 days exposure are included.

\begin{tabular}{lcccccc}
\hline Nest placement & No sound & $\begin{array}{c}\text { Predation } \\
\text { rate (\%) }\end{array}$ & Weak sound & $\begin{array}{c}\text { Predation } \\
\text { rate (\%) }\end{array}$ & $\begin{array}{c}\text { Medium } \\
\text { sound }\end{array}$ & $\begin{array}{c}\text { Predation } \\
\text { rate (\%) }\end{array}$ \\
\hline $\begin{array}{l}\text { In forest patches } \\
\begin{array}{c}\text { At Eurasian } \\
\text { magpie nests }\end{array}\end{array}$ & 90 & 47.8 & 32 & 46.9 & 58 & 43.1 \\
$\begin{array}{c}\text { At hooded crow } \\
\text { nests }\end{array}$ & 15 & 44.1 & 0 & & 85 & 89.4 \\
\hline
\end{tabular}

\section{Begging call playback treatment}

In 2001 and 2002, all nests were placed within 42 different forest patches (Table 1). Because the predation rate was quite independent of begging call playback treatment in this habitat (Table 2), I adjusted the experiment in the following years. Therefore, in 2003, 2004, 2010 and 2014 all nests were placed close to an active nest of Eurasian magpie or hooded crow, except four pairs placed in forests. Ascertaining the possible effect of begging call playback, and not of habitat differences, on nest predation was the main purpose of my experiments. As nests in human settlement areas were placed close to corvid nests, a higher predation was expected on these nests than on nests placed in forests (Mizera, 1988; Møller, 1988; Birkhead, 1991; Husby \& Olsen, 2017). I therefore assumed that it was not important that the two different habitats were monitored in different years. The use of data from multiple years should not be problematic because only small between-year variation in predation rate is found in this western part of the mid-boreal zone (Hoset \& Husby, 2018), and these are statistically controlled for in the analyses.

After I found a place with dense trees or bushes in a forest patch that made it possible to hide nests relatively well, I placed the two artificial nests as identical to each other as possible at the defined distance (see the section "Artificial nest experiments" above). Likewise, I searched for active corvid nests in human settlement areas where artificial nests could be placed nearby. After the two nests in a pair were attached to a tree or bush, I flipped a coin to decide which of them should have the sound playback. The other nest was equipped with an object of similar size and appearance placed similarly to the sound player. This ensured that the disturbed surroundings of nests with and nests without begging calls were physically similar.

The begging call playback treatment was based on the nestling begging calls of blue tit Cyanistes caeruleus chicks recorded for one minute at a nest box before fledging. Silent breaks lasting about $10 \mathrm{~s}$ in all followed the begging calls, and the strength (volume) of the begging calls varied during the one-minute period. During playback, the one-minute recording was looped. In 2001 and 2002, calls were played back at low volume in some of the nests, hereafter referred to as weak volume, which were audible to the human ear only within a distance of about $3 \mathrm{~m}$. 
For the other years, calls were played at higher volume than the low volume described above. These playback calls could be heard at a distance of about $10 \mathrm{~m}$ by a human in silent weather (Table 1). I refer to these as medium volume, because they are lower than many nestling begging calls from birds breeding naturally in the study areas. This volume might, however, mimic hungry, late-stage nestlings of small open-cup nesters (Tarwater et al., 2009). As I found no difference in predation rates for nests with low or medium volume (Table 2), only medium volume was used close to corvid nests (Table 1) and only no begging calls versus begging call playback was included in the statistical analyses.

I used a Minidisk (Sony Walkman MZ-R909) with a small external loudspeaker or Radio Cassette Recorder (Radionette LK-718) with internal loudspeaker for weak sound playback. I packed the Minidisk with the loudspeaker in a small green plastic bag, attached it just below the artificial nest and camouflaged it with the same type of vegetation as in the actual tree or bush. The Radio Cassette Recorder was larger than the Minidisk, and was therefore placed on the ground just below the nest; it was packed in a green plastic bag and was totally hidden by the same type of vegetation as in the surroundings. The same Radio Cassette Recorder was used to produce the medium volume playback and was hidden as described above. I also used a Logik MP3 player (Model L2MP309E) with an external loudspeaker (Hama $\mathrm{GmbH} \& \mathrm{Co} \mathrm{KG}$ ) to play medium-volume calls. The MP3 player was put inside a small loudspeaker shaped like a bag, protected by green plastic and hidden on the ground like the Radio Cassette Recorder. Empty batteries were exchanged during the first visit this was detected. In this way all sound players were positioned quite close to the artificial nests, at a maximum distance of about $0.5 \mathrm{~m}$ for players on the ground, and the other players placed directly below the artificial nest. All players were well hidden. As artificial nests without nestling begging playback were equipped with the same type of bag placed similarly to that for the nests with sounds, I assumed that the begging calls were the only difference between the two nests in each pair.

Both the Minidisk and MP3 players continued to play the begging calls until the batteries were empty. They lasted several days, and if the nest was predated, the players were used in a new setup without changing batteries. Empty batteries were therefore encountered at various numbers of days after the initiation of the experiment. The Radio Cassette Recorder contained an endless tape, and played continuously until the batteries were empty or the Auto Stop was activated if the tape became heavy to play. That means that nestling begging calls could be heard both day and night, and therefore it was equally possible to detect the nests independent of the diurnal activity patterns of the nest predators. Northern wheatear Oenanthe oenanthe parents in Swedish farmland habitat provide nestlings with food for an average of $19.5 \mathrm{~h}$ each day (Low et al., 2008), and this justifies the nestling begging calls being played continuously. In addition, all nests with nestling begging call playback were treated identically. 


\section{Predator identification}

A nest was considered predated if at least one of the eggs had been removed or damaged by a predator. Because the interpretation of marks on plasticine eggs might not give the same predator information as found in video analyses of the same nests (Thompson \& Burhans, 2004), I determined the predator only when marks were very distinctive and only distinguished between avian and mammalian predators. In a few nests, it was impossible to determine predator identity as the plasticine egg had been removed, contained no marks despite the fact that the quail egg had been predated, or egg marks were unidentifiable. No plasticine eggs had marks made by small rodents, snails or tits, which sometimes can be found in artificial nest experiments (Hoset \& Husby, 2018).

\section{Data analysis}

To analyse which factors influence the probability of a nest being predated, I used Generalized Linear Mixed Models (GLMM) to run a logistic regression with predation event (239 predated nests and 141 not predated) as the dependent variable, assuming binomially distributed error terms. Nestling playback-call treatment (yes or no), habitat (forest or close to corvid nest in human settlement areas), and their interaction were added as fixed factors. Year, region and pair number (see Table 1) were added as random factors to account for sampling features and the paired design of playback treatment. In a preliminary analysis, I included nest placement date as an independent variable, but this was not included in the final model because it did not affect the predation rate $\left(F_{10,366}=0.408, p=0.943\right)$. Because artificial nests away from known active corvid nests are in forests, and artificial nests close to active corvid nests are in human settlement areas, I analysed the probability of being predated with GLMM separately for the two habitats by removing habitat as fixed factor but keeping the other variables as in the full analysis.

I also used GLMMs to investigate which factors influenced the time it took from the start of nest exposure until the nest was predated using the same random structure as in the previous model. The data were restricted to predated nests with the predator known (bird or mammal, $N=117$ nests) in Model A, and thus excluded all nests with unknown predator $(N=122$ nests). Number of hours from the start of nest exposure was added as the dependent variable, assuming Poisson-distributed error terms. I added nestling playback-call treatment, habitat and predator identity (bird or mammal) and interactions between playback-call treatment and predator identity, and habitat and predator identity as fixed effects. In Model B, I included all predated nest $(N=239)$, including only playback treatment and habitat as independent variables.

All analyses were carried out using SPSS v. 24. 


\section{Results}

Of the 380 artificial nests (Table 1), 239 (62.9\%) were predated within 10 days of exposure. Birds predated 102 of the nests and mammals 15. For 122 nests, it was not possible to accurately determine predator identity. That meant that I was able to determine the predator in $48.5 \%$ of the nests, of which birds predated $87.1 \%$ and mammals $12.9 \%$. Mammals predated relatively more nests in forests than close to active corvid nests in human settlement habitat, and corvids predated relatively more nests when the nests were placed close to active corvid nests than in forests. Of the 15 nests predated by mammals, 13 (87\%) were in forests, while only 36 of 102 nests $(35 \%)$ predated by birds were in forests. This difference is significant (Fisher's exact probability test: $P<0.001$ ).

Artificial nests close to Eurasian magpie nests suffered significantly higher predation rates when sound was present compared to nests without sound present (Pearson Chi-square: $\chi^{2}=6.67, P=0.010$, Table 2). Nests close to hooded crow nests showed a nearly significant tendency towards the same pattern $\left(\chi^{2}=3.47\right.$, $P=0.065$ ) (Table 2). In further analyses, the results from the two corvid species are combined and referred to as nests close to corvid nests and compared with nests in forests.

The logistic regression model had good fit $\left(F_{3,376}=7.960, P<0.001\right)$ and showed that nestling begging playback treatment $\left(F_{1,376}=5.262, P=0.022\right)$, habitat $\left(F_{1,376}=15.309, P<0.001\right)$, and their interaction $\left(F_{1,376}=7.951, P=\right.$ $0.005)$ significantly influenced the probability that an artificial nest was predated. Predation rates were similar for artificial nests with and without playback treatment in forests, whereas nests close to corvid nests suffered higher predation rates than nests in forests and showed higher predation rates on nests with begging call playback than on nests without playback (Table 3, Fig. 2). The logistic regression model run for each of the two habitats separately stated that nestling begging playback treatment had a significant effect on the predation rate for nests close to active corvid nests $\left(F_{1,198}=10.698, P=0.001\right)$, but not in forested habitats $\left(F_{1,178}=0.182, P=0.671\right)$.

The GLMM analysis with time lapse before predation on all nests where the predator was identified $(N=117)$ showed a significant effect of all the independent

\section{Table 3.}

Model parameter estimates from the logistic regression with predation status as dependent variable, and playback treatment, habitat and their interaction as independent variables. The intercept represents nests without playback calls placed in the forest habitat.

\begin{tabular}{lrrrrrr}
\hline Parameter & Coefficient & SE & $t$ & $P$ & $\mathrm{CI}_{\text {Lower }}$ & $\mathrm{CI}_{\text {Upper }}$ \\
\hline Intercept & -0.946 & 0.772 & -1.225 & 0.222 & -2.464 & 0.573 \\
Playback treatment: yes & -0.135 & 0.317 & -0.425 & 0.671 & -0.759 & 0.489 \\
Habitat: at corvid nest & 2.515 & 0.848 & 2.967 & 0.003 & 0.848 & 4.182 \\
Playback treatment * Habitat & 1.447 & 0.513 & 2.820 & 0.005 & 0.438 & 2.457 \\
\hline
\end{tabular}




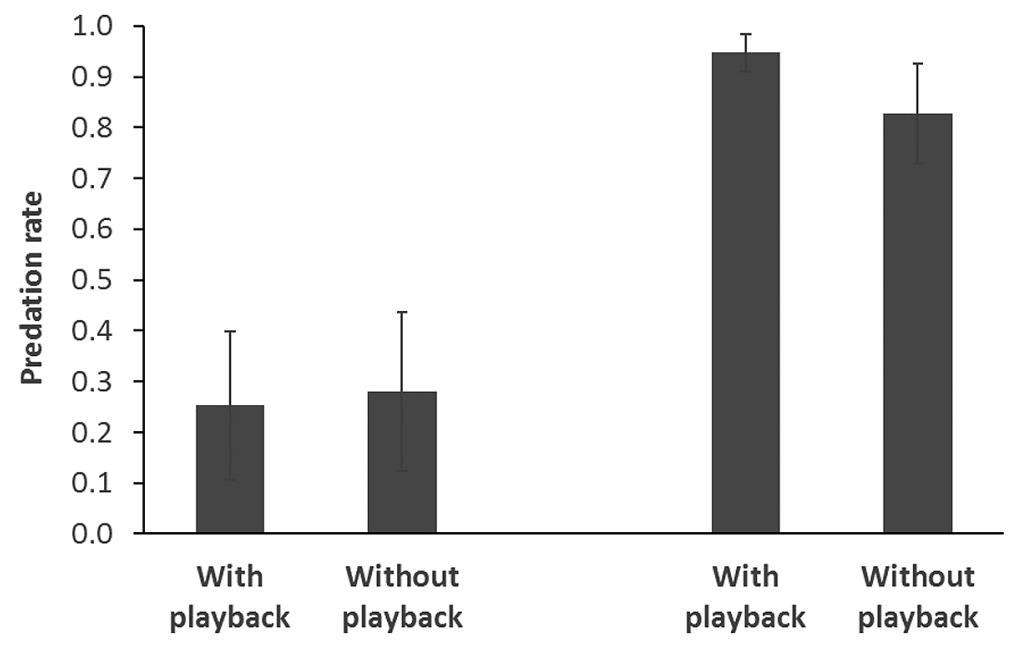

In forests

Close to corvid nests

Figure 2. Estimated mean predation rate \pm standard error for the interaction between begging call playback treatment and habitat. In each habitat, the means are given for both nests with and nests without nestling begging call playback.

variables used: begging call playback treatment, predator identity (bird or mammal), habitat, and the interactions between playback treatment and predator identity, and predator identity and habitat (Model A, Table 4). When all predated nests were included in the GLMM $(N=239)$, including only playback treatment and habitat as independent variables, only nestling begging playback significantly influenced time lapse until predation, and there were no effects of habitat (Model B, Table 4). The logistic regression model had good fit, both for Model A $\left(F_{5,111}=16.230\right.$,

\section{Table 4.}

Model fit estimates and variable fit from the GLMM model with number of hours until predation as dependent variable. Model A includes only nests with known predators, and has begging call playback treatment (yes or no), predator identity (bird or mammal), habitat (in forests or close to corvid nest) and the interactions between playback treatment and predator identity and between habitat and predator identity as independent variables. Model B includes all predated nests, and has playback treatment and habitat as independent variables.

\begin{tabular}{lllllr}
\hline & \multicolumn{2}{c}{ Model A } & & \multicolumn{2}{c}{ Model B } \\
\cline { 2 - 3 } \cline { 5 - 6 } Model term & \multicolumn{1}{c}{ Statistics } & Significance & & Statistics & Significance \\
\hline Playback treatment & $F_{1,111}=20.313$ & $P<0.001$ & & $F_{1,236}=146.980$ & $P<0.001$ \\
Predator & $F_{1,111}=59.987$ & $P<0.001$ & & \\
Habitat & $F_{1,111}=7.459$ & $P=0.007$ & & $F_{1,236}=0.096$ & $P=0.757$ \\
Playback treatment * Predator & $F_{1,111}=7.143$ & $P=0.009$ & & \\
Predator * Habitat & $F_{1,111}=32.323$ & $P<0.001$ & & \\
\hline
\end{tabular}


Table 5.

Model parameter estimates from GLMM model with number of hours until predation as dependent variable. Independent variables are as described in Table 4 for models A and B. The independent variables are compared with the intercept, which represents nests without playback calls, in forest, and with mammals as predator.

\begin{tabular}{lrrrrrr}
\hline A: Model term & Coefficient & SE & $\underline{t}$ & $\underline{P}$ & CI $_{\text {Lower }}$ & CI $_{\text {Upper }}$ \\
\hline Intercept & 159.042 & 21.573 & 7.327 & $<0.001$ & 116.294 & 201.790 \\
Playback treatment: yes & -46.925 & 12.913 & -3.634 & $<0.001$ & -72.513 & -21.337 \\
Predator ID: birds & -48.844 & 12.681 & -3.852 & $<0.001$ & -73.973 & -23.715 \\
Habitat: corvid nest & 99.064 & 22.791 & 4.347 & $<0.001$ & 53.902 & 144.225 \\
Playback treatment * Predator & 35.602 & 13.321 & 2.673 & $<0.001$ & 9.205 & 61.998 \\
Predator * Habitat & -107.301 & 18.873 & -5.685 & $<0.001$ & -144.700 & -69.902 \\
B: Model term & Coefficient & SE & $t$ & $P$ & $\mathrm{CI}_{\text {Lower }}$ & CI Upper \\
\hline Intercept & 115.552 & 7.626 & 15.153 & $<0.001$ & 100.529 & 130.575 \\
Playback treatment: yes & -15.480 & 1.277 & -12.124 & $<0.001$ & -17.995 & -12.964 \\
Habitat: corvid nest & -2.973 & 9.585 & -0.310 & 0.757 & -21.855 & 15.909 \\
\hline
\end{tabular}

$P<0.001)$ and Model B $\left(F_{2,236}=73.620, P<0.001\right)$. Thus, nestling begging calls reduced the time lapse before a nest was predated and birds predated the nests earlier than mammals (Table 5, Fig. 3). However, time lapse before predation is less affected by playback treatment when birds are predators than when mammals are. The latter predated nests with begging call playback significantly earlier than nests without playback calls (Fig. 3). The parameter estimates for the effect of

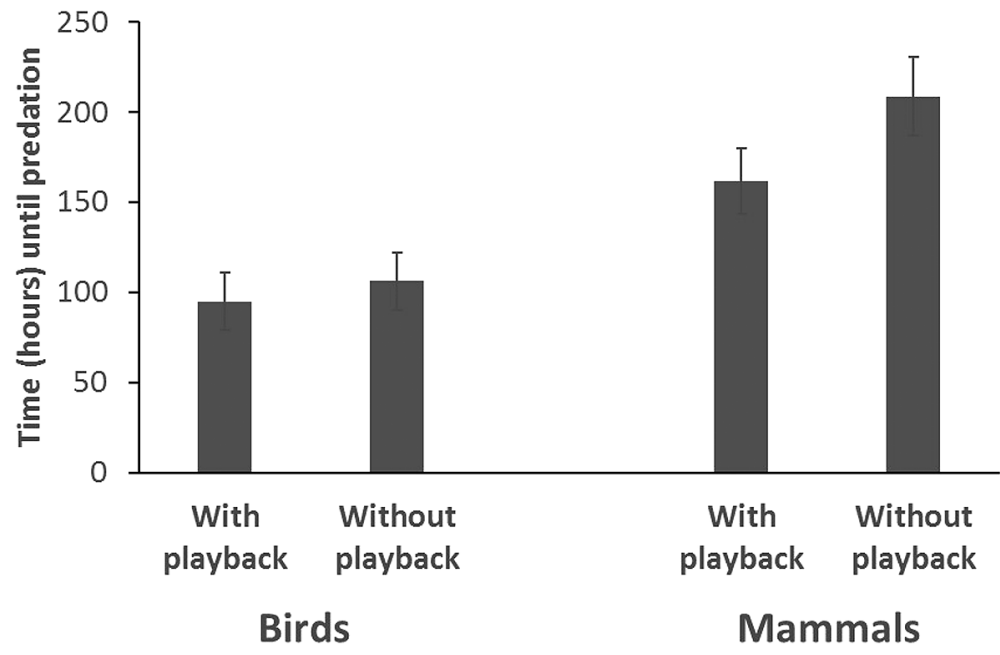

Figure 3. Estimated mean time laps (in hours) until predation \pm standard error for the interaction between begging call playback treatment and predator identity based on data with predated nests with known predator ( $N=117$ nests). 
playback treatment were similar whether all predated nests were included in the dataset (Model B, Table 4) or only nests with a known predator (Model A, Table 4). However, the effect of habitat was not consistent between Model A and Model B (Table 5).

In artificial nest pairs where both nests were predated $(N=66)$, nests with begging calls were predated earlier than nests without begging calls. This was the case both when I analysed all nests and only nests placed close to corvid nests (Fig. 4). I found that 44 nests with sound playback were predated first and 22 nests without sound playback were predated first (the two left columns in Fig. 4). Without any effect of the sounds I would expect 33 nests of each type to be predated first. This difference in observed and expected number of nests is almost significant (Table 6). Artificial nests close to corvid nests show the same non-significant tendency, but the lack of significance is probably because fewer nests were available for the analysis.

When only one of the two artificial nests in a pair was predated $(N=51)$, nests with nestling begging calls tended to be predated more often (Fig. 4). The differences between the observed number of predated nests with and without playback (Fig. 4) were close to or significantly different from an equal number for all nests, and significantly different for nests placed close to corvid nests (Table 6).

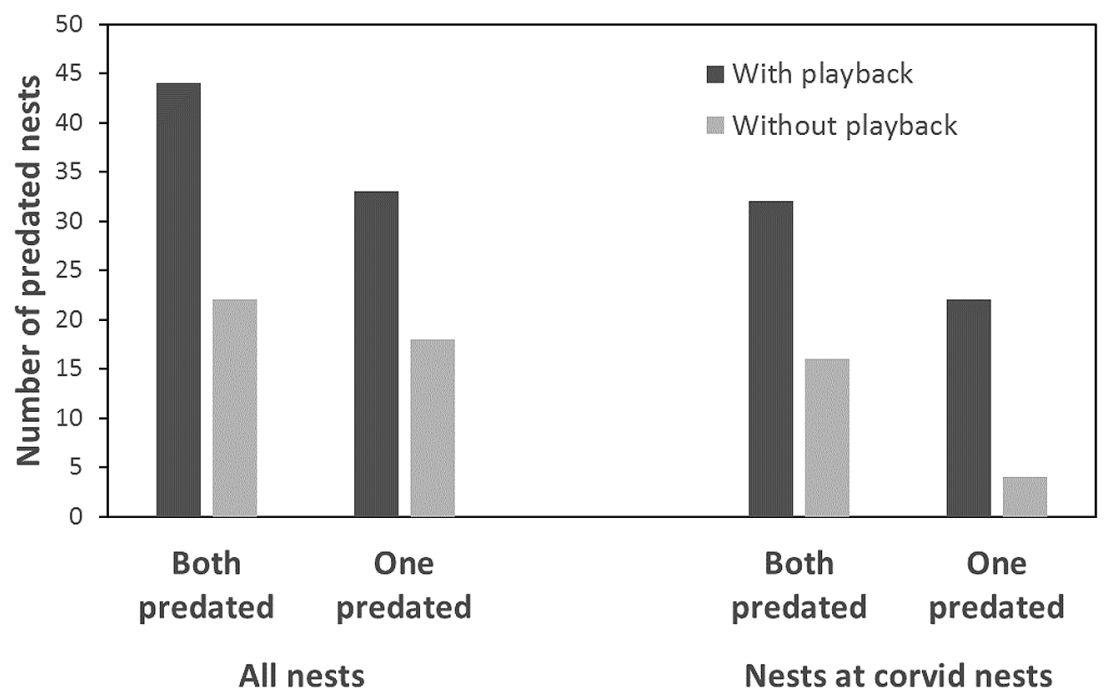

Figure 4. Number of predated nests with or without nestling begging calls. Included are nests from the whole dataset (all nests), or only nests placed close to active corvid nests. Both predated includes artificial nest pairs where both nests were predated, and the $y$-axis shows how many nests with playback and without playback were predated first of the two. One predated includes artificial nest pairs where only one of the two nests was predated, and how many of them were with and without playback, respectively. 
Table 6.

Pearson chi-square tests between the observed (Fig. 4) and a hypothetical equal number of predated nests with or without begging call playback. When both nests were predated, pairs where both nests in a pair were predated simultaneously ( $N=28$ for the all nests dataset and $N=17$ for nests close to active corvid nests) were not included. DF $=1$ in all tests. An equal number of predated nests with playback and predated nests without playback is expected only if predators do not use the begging calls as a cue to find the nests.

\begin{tabular}{llccc}
\hline Data & Fate of the nest pair & Number of nests & $\chi^{2}$ & Significance \\
\hline All nests & Both predated & 66 & 3.771 & $P=0.052$ \\
All nests & One predated & 51 & 2.276 & $P=0.131$ \\
At corvid nests & Both predated & 48 & 2.743 & $P=0.098$ \\
At corvid nests & One predated & 26 & 6.630 & $P=0.010$ \\
\hline
\end{tabular}

\section{Discussion}

The results of this artificial nest experiment clearly show that there is a cost to nestling begging calls. The nest predation risk increased and the time lapse until nest predation decreased with nestling begging call playback compared with similar nests without playback. It is therefore reasonable to believe that nest predation exerts a selection pressure on the nestling begging behavior itself, or on other adaptations to reduce the impact of predators using auditory cues (Magrath et al., 2010; Ibanez-Alamo et al., 2015). Parental calls can make the nestlings silent (Halupka, 1998a; Platzen \& Magrath, 2004; McIntyre et al., 2014) or reduce the strength (volume) of their begging (Anderson et al., 2010). Sounds from the predators can also make the chicks silent (Magrath et al., 2007; Haff \& Magrath, 2011), or the begging calls can have higher frequencies, making them harder for a nest predator to locate (Briskie et al., 1999). Confounding variables might explain possible positive relationships between nestling begging intensity and nest predation rates (Magrath et al., 2010). On the other hand, some investigations of natural nests did not show any effect of nestling begging on nest predation (Halupka, 1998b; Yasukawa, 2016), but this is reasonable if any negative costs of the begging can be mitigated by other factors, including parental behavior (Magrath et al., 2010). Because of this, the use of artificial nests with playbacks of nestling calls gives the most direct evidence for the nest predation cost of begging calls itself without intervening variables (Magrath et al., 2010). This implies that the costs incurred by nestling begging calls can be more pronounced in artificial nest experiments than on natural nests. However, the results in this experiment undoubtedly show us that there is a trade-off between nestling begging calls and the risk of nest predation, which again influences several life history parameters (see Introduction).

Further, this experiment showed that nestling begging calls increase the nest predation rate in nests placed close to active corvid nests. Most probably magpies and hooded crows are the main nest predators here, because they strongly defend the all-purpose territories in which they nest, feed and spend most of their time against 
nest predators from other species as well as conspecifics during the breeding season (Birkhead, 1991; Cramp \& Perrins, 1994). This assumption is supported by the fact that nearly all artificial nests placed close to active corvid nests were predated by birds. There are hardly any experiments intended to identify the cues used by nest predators, so our understanding of this is limited (Santisteban et al., 2002; Pelech et al., 2010). This experiment is therefore a valuable contribution in this field. Earlier assumptions that predating birds are only visually oriented when searching for nests (Santisteban et al., 2002; Magrath et al., 2010; Ibanez-Alamo et al., 2015) do not seem to be valid.

In this experiment, I use paired artificial nests, one with and one without the sounds of nestling begging calls. It is therefore important that both of the pairwise nests looked the same and were placed similarly to reduce possible bias in the experiment. It would have been nearly impossible to find enough natural nests that fit into the detailed protocol and provide a large enough amount of data. However, the reliability of the results coming from artificial nest experiments has received some criticism, mostly because their predation rates often differ from that of natural nests (Martin, 1987; Storaas, 1988; Willebrand \& Marcström, 1988; Buler \& Hamilton, 2000; Burke et al., 2004). However, artificial nest experiments might demonstrate similar trends as natural nests in the ecological variables studied in some experiments (Yahner \& Delong, 1992; Major et al., 1994; Kurucz et al., 2012), but not always (Moore \& Robinson, 2004). In this study area, artificial and natural nests had similar predation rates across ecological variables (Hoset \& Husby, unpubl.). Therefore, and because the between-year variation in predation rates in our study area was low (Hoset \& Husby, 2018), I trust that the artificial nests in this welldesigned experiment give reliable results. There are two ways nestling begging calls can attract predators to the nest: indirectly by stimulating parents to increase feeding rate, and directly by giving predators acoustic cues (Magrath et al., 2010). Another advantage of using artificial nests is that we can measure the direct effect caused by the begging calls alone without influence from variation in feeding rate or other aspects of parental and nestling behavior. It is therefore recommended to use artificial nests in experiments like the one in this paper (Magrath et al., 2010).

The artificial nests were placed close to active corvid nests in human settlement areas starting early in March. Corvids spend a lot of time in their territories and defend them against conspecific intruders and other nest predators already in February and especially in March and April (Husby \& Olsen, 2017). The artificial nests close to corvid nests suffered a high predation rate already from the beginning of March (data not presented). On the other hand, only six of the 180 nests in forest patches were placed in March and none of them became predated. All the other 174 nests in this habitat were exposed from the last ten days of April to the end of June. Because of the pairwise layout of the artificial nests, there should be no bias between the two groups of nests (sound playback or no sound), only a possible seasonal variation in the corvids' ability to find the nests (Husby \& Hoset, in press). The low nest predation rate in forest patches compared to nests close to corvid nests are not caused 
by variation in nest exposure date between the two habitats. In fact, the difference in nest predation rates between the two habitats would probably have been larger if the experiment in the forest patches had been fully active from early in March, outside the season when nest predation rate is highest in the area (Husby \& Hoset, in press).

I used recordings of begging calls from blue tit Cyanistes caeruleus in the experiments. Blue tit is a cavity-nesting passerine, and it is normally very difficult for a corvid and many other nest predators to take small chicks from the bottom of the nests. This might decrease the predators' interest to search for and try to depredate such nests, so any findings in this experiment with sounds from a cavity-nesting passerine can potentially be even stronger with begging calls from an open-cup nester where it is quite easy to take the nest contents. However, corvids are able to grab nestlings sitting in the nest opening shortly before fledging, and can take unexperienced fledglings (Husby \& Olsen, 2017). A Eurasian magpie removal experiment in France increased productivity in only one of 10 investigated passerine species, and that was blue tit (Chiron \& Julliard, 2007). As the number of adult blue tits was not lower with magpies present, the lower number of juveniles with magpies present indicates that magpies are able to catch them. The high predation rate in my experiment shows that nest predators pay attention to nestling begging calls from this cavity nester, but future studies should use begging calls from open-cup nesting birds to complement this study.

\section{Acknowledgements}

I acknowledge all landowners for permission to perform this study, Karen Tvedt for assistance in the fieldwork, Katrine S. Hoset, Staffan Roos and one anonymous referee for valuable comments to the manuscript, and Heidi H. Grosch for improving the English text. The manuscript was submitted to Animal Biology after initial evaluation in Peerage of Science (www.peerageofscience.org).

\section{References}

Anderson, M.G., Brunton, D.H. \& Hauber, M.E. (2010) Species specificity of grey warbler begging solicitation and alarm calls revealed by nestling responses to playbacks. Anim. Behav., 79, 401-409.

Badyaev, A.V. \& Ghalambor, C.K. (2001) Evolution of life histories along elevational gradients: tradeoff between parental care and fecundity. Ecology., 82, 2948-2960.

Bengtsson, H. \& Rydén, O. (1983) Parental feeding rate in relation to begging behavior in asynchronously hatched broods of the great tit Parus major. An experimental study. Behav. Ecol. Sociobiol., 12, 243-251.

Birkhead, T. (2012) Bird Sense. What It's Like to be a Bird. Bloomsbury, London, UK.

Birkhead, T.R. (1991) The Magpies. The Ecology and Behaviour of Black-Billed and Yellow-Billed Magpies. Poyser, London, UK.

Briskie, J.V., Martin, P.R. \& Martin, T.E. (1999) Nest predation and the evolution of nestling begging calls. Proc. R. Soc. B Biol. Sci., 266, 2153-2159. 
Buler, J.J. \& Hamilton, R.B. (2000) Predation of natural and artificial nests in a southern pine forest. Auk, 117, 739-747.

Burke, D.M., Eliliott, K., Moore, L., Dunford, W., Nol, E., Phillips, J., Holmes, S. \& Freemark, K. (2004) Patterns of nest predation on artificial and natural nests in forests. [Patrones de depredación de nidos artificiales y naturales en bosques.]. Conserv. Biol., 18, 381-388.

Chiron, F. \& Julliard, R. (2007) Responses of songbirds to magpie reduction in an urban habitat. J. Wildl. Manage., 71, 2624-2631.

Colyn, R.B., Radloff, F.G.T. \& O'Riain, M.J. (2018) Camera trapping mammals in the scrubland's of the cape floristic kingdom - the importance of effort, spacing and trap placement. Biodivers. Conserv., 27, 503-520.

Cramp, S. \& Perrins, C.M. (1994) The Birds of the Western Palearctic, Vol. 8, Crows to Finches. Oxford University Press, Oxford, UK.

Cutler, T.L. \& Swann, D.E. (1999) Using remote photography in wildlife ecology: a review. Wildl. Soc. Bull., 27, 571-581.

Dearborn, D.C. (1999) Brown-headed cowbird nestling vocalizations and risk of nest predation. Auk, $116,448-457$.

Gates, J.E. \& Gysel, L.W. (1978) Avian nest dispersion and fledging success in field-forest ecotones. Ecology, 59, 871-883.

Guppy, M., Guppy, S., Marchant, R., Priddel, D., Carlile, N. \& Fullagar, P. (2017) Nest predation of woodland birds in south-east Australia: importance of unexpected predators. Emu, 117, 92-96.

Haff, T.M. \& Magrath, R.D. (2011) Calling at a cost: elevated nestling calling attracts predators to active nests. Biol. Lett., 7, 493-495.

Halupka, K. (1998a) Vocal begging by nestlings and vulnerability to nest predation in meadow pipits Anthus pratensis; to what extent do predation costs of begging exist? Ibis, 140, 144-149.

Halupka, K. (1998b) Nest predation in meadow pipits Anthus pratensis in natural conditions. Ornis Fenn., 75, 139-143.

Haskell, D. (1994) Experimental evidence that nestling begging behavior incurs a cost due to nest predation. Proc. R. Soc. B Biol. Sci., 257, 161-164.

Haskell, D.G. (1995) Forest fragmentation and nest predation: are experiments with Japanese quail eggs misleading? Auk, 112, 767-770.

Haskell, D.G. (1999) The effect of predation on begging-call evolution in nestling wood warblers. Anim. Behav., 57, 893-901.

Hewitt, D.G., Keppie, D.M. \& Stauffer, D.F. (2001) Predation effects on forest grouse recruitment. Wildl. Soc. Bull., 29, 16-23.

Hinde, C.A. \& Kilner, R.M. (2007) Negotiations within the family over the supply of parental care. Proc. R. Soc. B Biol. Sci., 274, 53-60.

Hoset, K. \& Husby, M. (2018) Small between-year variations in nest predation rates are not related with between-year differences in predator identity. Ecoscience, 25, 199-208.

Hoset, K. \& Husby, M. (Unpublished) Comparability of Predation Rates between Natural and Artificial Nests Depends on Nest Design, Forest Gradient Location and Exposure Time.

Husby, M. \& Hoset, K. (In press) Seasonal variation in nest predation rates in boreal forests. J. Ornithol. DOI:10.1007/s10336-018-1563-y.

Husby, M. \& Olsen, J.B. (2017) Skjareboka. Ask Forlag, Halden, Norway.

Ibanez-Alamo, J.D., Magrath, R.D., Oteyza, J.C., Chalfoun, A.D., Haff, T.M., Schmidt, K.A., Thomson, R.L. \& Martin, T.E. (2015) Nest predation research: recent findings and future perspectives. J. Ornithol., 156, S247-S262.

Kilner, R.M. (2006) The evolution of egg colour and patterning in birds. Biol. Rev., 81, 383-406. 
Korpimäki, E., Norrdahl, K. \& Rintajaskari, T. (1991) Responses of stoats and least weasels to fluctuating food abundances: is the low phase of the vole cycle due to mustelid predation? Oecologia, $88,552-561$.

Kurucz, K., Bertalan, L. \& Purger, J.J. (2012) Survival of blackbird (Turdus merula) clutches in an urban environment: experiment with real and artificial nests. North-West. J. Zool., 8, 362-364.

Langston, R.H.W., Liley, D., Murison, G., Woodfield, E. \& Clarke, R.T. (2007) What effects do walkers and dogs have on the distribution and productivity of breeding European Nightjar Caprimulgus europaeus? Ibis, 149, 27-36.

Leech, S.M. \& Leonard, M.L. (1997) Begging and the risk of predation in nestling birds. Behav. Ecol., 8, 644-646.

Lewis, K.P. \& Montevecchi, W.A. (1999) Predation on different size quail eggs in an artificial nest study in western Newfoundland. Can. J. Zool., 77, 1170-1173.

Lima, S.L. (2009) Predators and the breeding bird: behavioral and reproductive flexibility under the risk of predation. Biol. Rev., 84, 485-513.

Low, M., Eggers, S., Arlt, D. \& Part, T. (2008) Daily patterns of nest visits are correlated with ambient temperature in the Northern Wheatear. J. Ornithol., 149, 515-519.

Madden, C.F., Arroyo, B. \& Amar, A. (2015) A review of the impacts of corvids on bird productivity and abundance. Ibis, 157, 1-16.

Magrath, R.D., Pitcher, B.J. \& Dalziell, A.H. (2007) How to be fed but not eaten: nestling responses to parental food calls and the sound of a predator's footsteps. Anim. Behav., 74, 1117-1129.

Magrath, R.D., Haff, T.M., Horn, A.G. \& Leonard, M.L. (2010) Calling in the face of danger: predation risk and acoustic communication by parent birds and their offspring. In: H.J. Brockmann, T.J. Roper, M. Naguib, K.E. Wynne-Edwards, J.C. Mitani \& L.W. Simmons (Eds) Advances in the Study of Behavior, vol. 41, pp. 187-253. Elsevier Academic Press, San Diego, CA, USA.

Major, R.E., Pyke, G.H., Christy, M.T., Gowing, G. \& Hill, R.S. (1994) Can nest predation explain the timing of the breeding season and the pattern of nest dispersion of New Holland honeyeaters. Oikos, 69, 364-372.

Martin, T.E. (1987) Artificial nest experiments - effects of nest appearance and type of predator. Condor, 89, 925-928.

Martin, T.E. (1993a) Nest predation among vegetation layers and habitat types - revising the dogmas. Am. Nat., 141, 897-913.

Martin, T.E. (1993b) Nest predation and nest sites - new perspectives on old patterns. Bioscience, 43, 523-532.

Martin, T.E. (1995) Avain life-history evolution in relation to nest sites, nest predation, and food. Ecol. Monogr., 65, 101-127.

Martin, T.E., Martin, P.R., Olson, C.R., Heidinger, B.J. \& Fontaine, J.J. (2000a) Parental care and clutch sizes in North and South American birds. Science, 287, 1482-1485.

Martin, T.E., Scott, J. \& Menge, C. (2000b) Nest predation increases with parental activity: separating nest site and parental activity effects. Proc. R. Soc. B Biol. Sci., 267, 2287-2293.

McDonald, P.G., Wilson, D.R. \& Evans, C.S. (2009) Nestling begging increases predation risk, regardless of spectral characteristics or avian mobbing. Behav. Ecol., 20, 821-829.

McIntyre, E., Horn, A.G. \& Leonard, M.L. (2014) Do nestling tree swallows (Tachycineta bicolor) respond to parental alarm calls? Auk, 131, 314-320.

Mizera, T. (1988) An ecological study of the synanthropic avifauna of the Solacz district of Poznan in 1975-1984. Acta Zool. Cracov., 31, 3-64.

Møller, A.P. (1988) Nest predation and nest site choice in passerine birds in habitat patches of different sizes: a study of magpies and blackbirds. Oikos, 53, 215-221. 
Moore, R.P. \& Robinson, W.D. (2004) Artificial bird nests, external validity, and bias in ecological field studies. Ecology, 85, 1562-1567.

Muchai, M. \& du Plessis, M.A. (2005) Nest predation of grassland bird species increases with parental activity at the nest. J. Avian Biol., 36, 110-116.

Nolan, V. (1963) Reproductive success of birds in a deciduous scrub habitat. Ecology, 44, 305-313.

Pelech, S.A., Smith, J.N.M. \& Boutin, S. (2010) A predator's perspective of nest predation: predation by red squirrels is learned, not incidental. Oikos, 119, 841-851.

Platzen, D. \& Magrath, R.D. (2004) Parental alarm calls suppress nestling vocalization. Proc. R. Soc. B Biol. Sci., 271, 1271-1276.

Ricklefs, R.E. (1969) An Analysis of Nesting Mortality in Birds. Smithsonian Contrib. Zool., 9. iv+48 pp.

Roos, S. (2002) Functional response, seasonal decline and landscape differences in nest predation risk. Oecologia, 133, 608-615.

Santema, P., Schlicht, E., Schlicht, L. \& Kempenaers, B. (2017) Blue tits do not return faster to the nest in response to either short- or long-term begging playbacks. Anim. Behav., 123, 117-127.

Santisteban, L., Sieving, K.E. \& Avery, M.L. (2002) Use of sensory cues by fish crows Corvus ossifragus preying on artificial bird nests. J. Avian Biol., 33, 245-252.

Searcy, W.A. \& Yasukawa, K. (2017) Eavesdropping and cue denial in avian acoustic signals. Anim. Behav., 124, 273-282.

Sieving, K.E. (1992) Nest predation and differential insular extinction among selected forest birds of central Panama. Ecology, 73, 2310-2328.

Slagsvold, T., Sandvik, J., Rofstad, G., Lorentsen, Ø. \& Husby, M. (1984) On the adaptive value of intraclutch egg-size variation in birds. Auk, 101, 685-697.

Sloan, S.S., Holmes, R.T. \& Sherry, T.W. (1998) Depredation rates and predators at artificial bird nests in an unfragmented northern hardwood forest. J. Wildl. Manage., 62, 529-539.

Storaas, T. (1988) A comparison of losses in artificial and naturally-occurring capercaillie nests. J. Wildl. Manage., 52, 123-126.

Tarwater, C.E., Kelley, J.P. \& Brawn, J.D. (2009) Parental response to elevated begging in a high predation, tropical environment. Anim. Behav., 78, 1239-1245.

Temple, S.A. \& Cary, J.R. (1988) Modelling dynamics of habitat-interior bird populations in fragmented landscapes. Conserv. Biol., 2, 340-347.

Thompson, F.R. \& Burhans, D.E. (2004) Differences in predators of artificial and real songbird nests: evidence of bias in artificial nest studies. Conserv. Biol., 18, 373-380.

Willebrand, T. \& Marcström, V. (1988) On the danger of using dummy nests to study predation. Auk, 105, 378-379.

Yahner, R.H. \& Delong, C.A. (1992) Avian predation and parasitism on artificial nests and eggs in two framented landscapes. Wilson Bull., 104, 162-168.

Yasukawa, K. (2016) Do begging calls from nestling red-winged blackbirds (Agelaius phoeniceus) increase nest predation? Wilson J. Ornithol., 128, 879-884. 